7 Van den Akker EH, Schilder AG, Kemps YJ, van Balen FA, Hordijk GJ, Hoes AW. Current indications for (adeno)tonsillectomy in children: a survey in the Netherlands. Int J Pediatr Otorhinolaryngol 2003;67:603-7.

8 Blair RL, McKerrow WS, Carter NW, Fenton A. The Scottish tonsillectomy audit. Audit Sub-Committee of the Scottish Otolaryngological Society.J Laryngol Otol 1996;110(suppl 20):1-25.

9 Donnelly MJ, Quraishi MS, McShane DP. Indications for paediatric tonsillectomy: GP versus consultant perspective. J Laryngol Otol 1994;108:131-4.

10 Capper R, Canter RJ. Is there agreement among general practitioners, paediatricians and otolaryngologists about the management of children with recurrent tonsillitis? Clin Otolaryngol 2001;26:371-8.

11 Faulconbridge RV, Fowler S, Horrocks J, Topham JH. Comparative audit of tonsillectomy. Clin Otolarymol 2000:25:110-7.

12 Brouillette R, Hanson D, David R, Klemka L, Szatkowski A, Fernbach S, et al. A diagnostic approach to suspected obstructive sleep apnea in hildren. J Pediatr 1984:105:10-4.

13 Fekkes M, Theunissen NC, Brugman E, Veen S, Verrips EG, Koopman HM, et al. Development and psychometric evaluation of the TAPQoL: a health-related quality of life instrument for 1-5-year-old children. Qua Life Res 2000;9:961-72.
14 Raat H, Bonsel GJ, Essink-Bot ML, Landgraf JM, Gemke RJ. Reliability and validity of comprehensive health status measures in children: the child health questionnaire in relation to the health utilities index $J$ Clin Epidemiol 2002;55:67-76.

15 Van Staaij BK, Rovers MM, Schilder AG, Hoes AW. Accuracy and feasibility of daily infrared tympanic membrane temperature measurements in the identification of fever in children. Int J Pediatr Otorhinolaryngol 2003;67:1091-7.

16 Stewart MG, Friedman EM, Sulek M, deJong A, Hulka GF, Bautista MH, et al. Validation of an outcomes instrument for tonsil and adenoid disease. Arch Otolaryngol Head Neck Surg 2001;127:29-35.

17 Van den Akker EH, Rovers MM, van Staaij BK, Hoes AW, Schilder AG. Representativeness of trial populations: an example from a trial of Representativeness of trial populations: an example from a trial

18 Eskerud JR, Laerum E, Fagerthun H, Lunde PKM, Naess A. Fever in general practice. 1. Frequency and diagnoses. Fam Pract 1992;9:263-9.

19 Soman M. Characteristics and management of febrile young children seen in a university family practice. J Fam Pract 1985;21:117-22. (Accepted 6 July 2004)

doi $10.1136 /$ bmj.38210.827917.7C

\title{
Commentary: Watchful waiting is useful for children with recurrent throat infections
}

\author{
Paul Little
}

Primary Medical Care, Community Clinical Sciences Division, Southampton University, Aldermoor Health Centre, Southampton SO16 5ST

Paul Little professor of primary care research psl3@soton.ac.uk
Van Staaij et al's study is a welcome addition to a controversial subject. ${ }^{1}$ It shows that for children with moderately frequent throat infections (on average three in the previous year) a "wait and see" approach results in acceptable control of symptoms and avoids postoperative pain and complications ( $1 \%$ requiring operative surgery for haemorrhage, and $2.6 \%$ having severe nausea or dehydration). The major limitation of the study is the large number of children from the watchful waiting group who had tonsillectomy (34\%). Since a per protocol analysis was not done-that is, comparing those who had tonsillectomy with those who did not, controlling for severity indices-it cannot be concluded that tonsillectomy in itself is ineffective but simply that immediate tonsillectomy is not effective. The data from this trial, however, match data from a similar trial, which reported little symptomatic benefit and a significant rate of complications (7\%) among children who had tonsillectomy for more severe symptoms. ${ }^{2}$

Should children with more severe symptoms be offered surgery? With the normal caveats about subgroup analysis, there was some evidence from Van Staaij et al's trial that those more severely affected (three or more infections a year) had some benefit from immediate tonsillectomy-one less episode of sore throat. The earlier Paradise trial assessed tonsillectomy among selected children with severe symptoms ${ }^{3}$ - the "Paradise" criteria of seven or more throat infections in the preceding year, or five or more a year for each of the preceding two years, or three or more a year for each of the preceding three years. This trial showed a reduction of around one episode, rated as moderate or severe ( 3 of 38 surgical patients $v 41$ of 35 controls); however, the trial was small and was criticised by the Cochrane review for imbalances of important baseline characteristics (the author argued that this was unlikely to affect inferences). ${ }^{4}$

Given the paucity of evidence and controversy about existing evidence, more data are clearly needed on tonsillectomy among children with recurrent throat infections, and particularly data on non-surgical approaches. Until this evidence is available it would be reasonable for doctors to share with parents the probable benefits of surgery-among children with the Paradise criteria, one less episode of moderately severe or severe sore throat a year; among children with at least three infections in the past year, one less episode of sore throat a year-but also the important harms of operation-a complication rate of $4-7 \%$. For the remaining children, doctors should probably not offer tonsillectomy.

Competing interests. PL has been paid for two consultancy sessions from Abbott Pharmaceuticals for antibiotics for complications of respiratory tract infections.

1 Van Staaij BK, van den Akker, EH, Rovers MM, Hordijk GJ, Hoes AW, Schilder AGM. Effectiveness of adenotonsillectomy in children with mild symptoms of throat infections or adenotonsillar hypertrophy: open, ransymptoms of throat infections or ad
domised controlled trial. BMI 2004;

2 Paradise J, Bluestone C, Colborn D, Bernard B, Rockette H, Kurs-Lasky M. Tonsillectomy and adenotonsillectomy for recurrent throat infection in moderately affected children. Pediatrics 2002;110:7-15

3 Paradise J, Bluestone C, Bachman R, Colborn D, Bernard B, Taylor F, et al Efficacy of tonsillectomy for recurrent throat infection in severely affected children: results of parallel randomized and nonrandomized clinical trials. N Engl J Med 1984;310:674-83.

4 Burton M, Towler B, Glasziou P. Tonsillectomy versus non-surgical treatment for chronic/recurrent acute tonsillitis. Cochrane Database Syst Rev 2000;(2):CD001802.

\section{Endpiece}

\section{My wife and my mistress}

Medicine is my lawful wife, but literature is my mistress. When I'm bored with one, I spend the night with the other.

Anton Chekhov (1860-1904), Russian writer, dramatist, and doctor

Fred Charatan, retired geriatric physician, Florida 